\title{
Fostering Europe's Future Physician-Scientists: An Interview with European MD/PhD Association Chairman Dr. André dos Santos Rocha
}

Paul M. Ryan, ${ }^{1,2}$ André dos Santos Rocha. ${ }^{2,3}$

\begin{abstract}
The Interview
Dr. André dos Santos Rocha is a Resident Physician in Intensive Care Medicine at Anaesthesiology and a current MD-PhD student in the Department of Acute Medicine at the University of Geneva (Figure 1). In parallel, he is also the current Chairman of the European MD/PhD Association (EMPA), a role in which he coordinates a diverse group of highly-driven MD-PhD students. EMPA is a not-for-profit organisation which was founded with the central aims of bringing together MD-PhDs from across Europe, fostering a comfortable setting for networking, promoting European scientific collaborations and support for research, and mobilizing European MD-PhD students. One of the main mediums through which EMPA achieves a number of these lofty goals is their annual conference, which is typically held in conjunction with one of the national associations. I met with Dr. Dos Santos Rocha after the recent European and Swiss MD-PhD Conference in Geneva to discuss his experience in this role and what the future holds for EMPA.
\end{abstract}

Paul MacDaragh Ryan (PMR): Good afternoon, André. Many thanks for agreeing to educate us on EMPA and your involvement in the organisation. To start, can you tell us a bit about your career to date, your research and what drew you into medicine initially?

Dr. André dos Santos Rocha (ASDR): Hi Paul! Thank you for joining EMPA and especially for reaching out to me for this conversation. My career to date has been divided between a number of European countries. I attended medical school in Lisbon, completing the final two years of my undergraduate education in Paris and London, respectively. It is somewhat difficult for me to go back to the very first moments that drove me into medicine. I must have been 12 or 13 years old when, already fascinated by the natural sciences, my older cousin brought me to visit the Intensive Care Unit (ICU) "space shuttle" room at one of the biggest hospitals in Portugal. Of course, it was difficult not to be fascinated by this back at that age. Many years later, I was attracted by medicine for its humanistic aspects, the art of its practice and the endless innovation which keeps it in motion.

After graduating from my undergraduate studies in 2013, I launched into residency in ICU/Anaesthesiology in Switzerland. Subsequently, in 2017, I put my clinical training on hold to pursue an MD-PhD programme in Geneva. My research focuses on respiratory biophysics and pathophysiology during mechanical ventilation. Naturally, my choices and career in research were guided by my experience in the ICU.

PMR: What is the one piece of advice which you would give to someone who is currently considering applying to an MD-PhD program?
Figure 1. Dr. André dos Santos Rocha, University of Geneva MD-PhD Student a $\mathrm{EU} \mathrm{MD} / \mathrm{PhD}$ Association Chairman. Pictured here with a Ceneva EMPA Conference attendee.

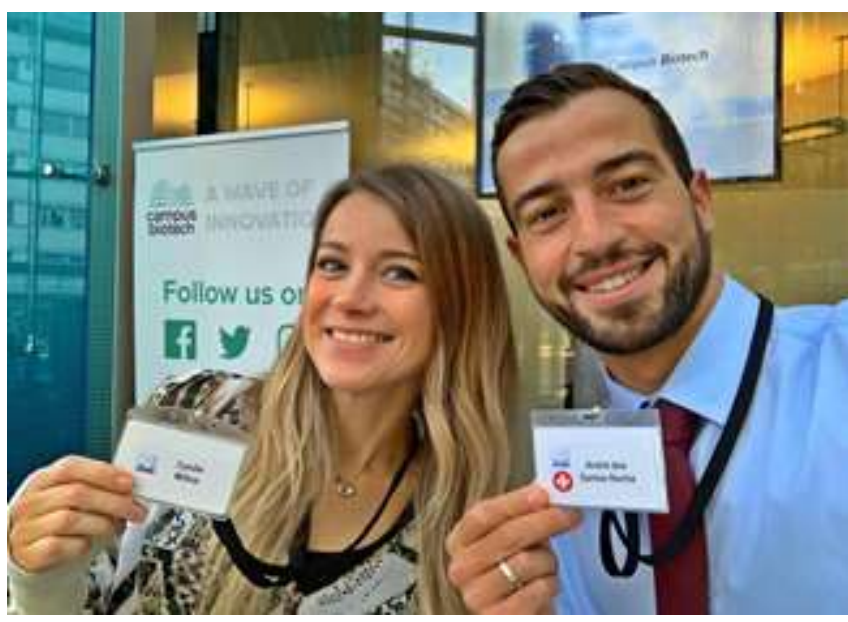

ADSR: I would rather say that if someone is actively considering applying to such a research track, they very likely possess the core skills which fuel research: motivation and scientific curiosity. With this in mind, now is the right moment to dive into it without fear. It might seem long, laborious and disconnected from the usual clinician track, but you will probably become one of a kind amongst your peers. To hold an MD-PhD title and education is rarely undervalued.

PMR: What have been the biggest challenges and rewards of the MD$P h D$ route for you so far?

ADSR: I guess the challenges and struggles are quite similar to all of us: to find enough financial and personal support, as well as to have guidance for both our experiments and careers. It is of course challenging to attain a salary which is equivalent to our peers/colleagues who are solely performing clinical duties. On a personal note, I would say that becoming a student again many years after leaving medical school was the biggest challenge. As a junior doctor, my sense of autonomy and fulfilment increased exponentially. You can imagine what it was like at first to go back to didactic lectures, amphitheatres and a laboratory bench as a full-time job.

\footnotetext{
University College Cork, Cork. Ireland.

European MD-PhD Association, Groningen, The Netherlands.

${ }_{3}$ Department of Anesthesiology, Pharmacology and Surgery Intensive Care, University of Geneva, Geneva, Switzerland
}

About the Author: Paul MacDaragh Ryan is an incoming Academic Track Junior Doctor in Cork, Ireland. He holds a PhD which investigated the role of the gut microbiome in host cardiometabolic function. Paul is a current Evidence Synthesis Ireland Fellow and an Associate Editor at International Journal of Medical Students. 
Figure 2. Delegates of the $8^{\text {th }} \mathrm{EU} \mathrm{MD} / \mathrm{PhD}$ Association Conference. More than 70 delegates representing 15 nationalities attended the meeting at Campus Biotech, Geneva, Switzerland.

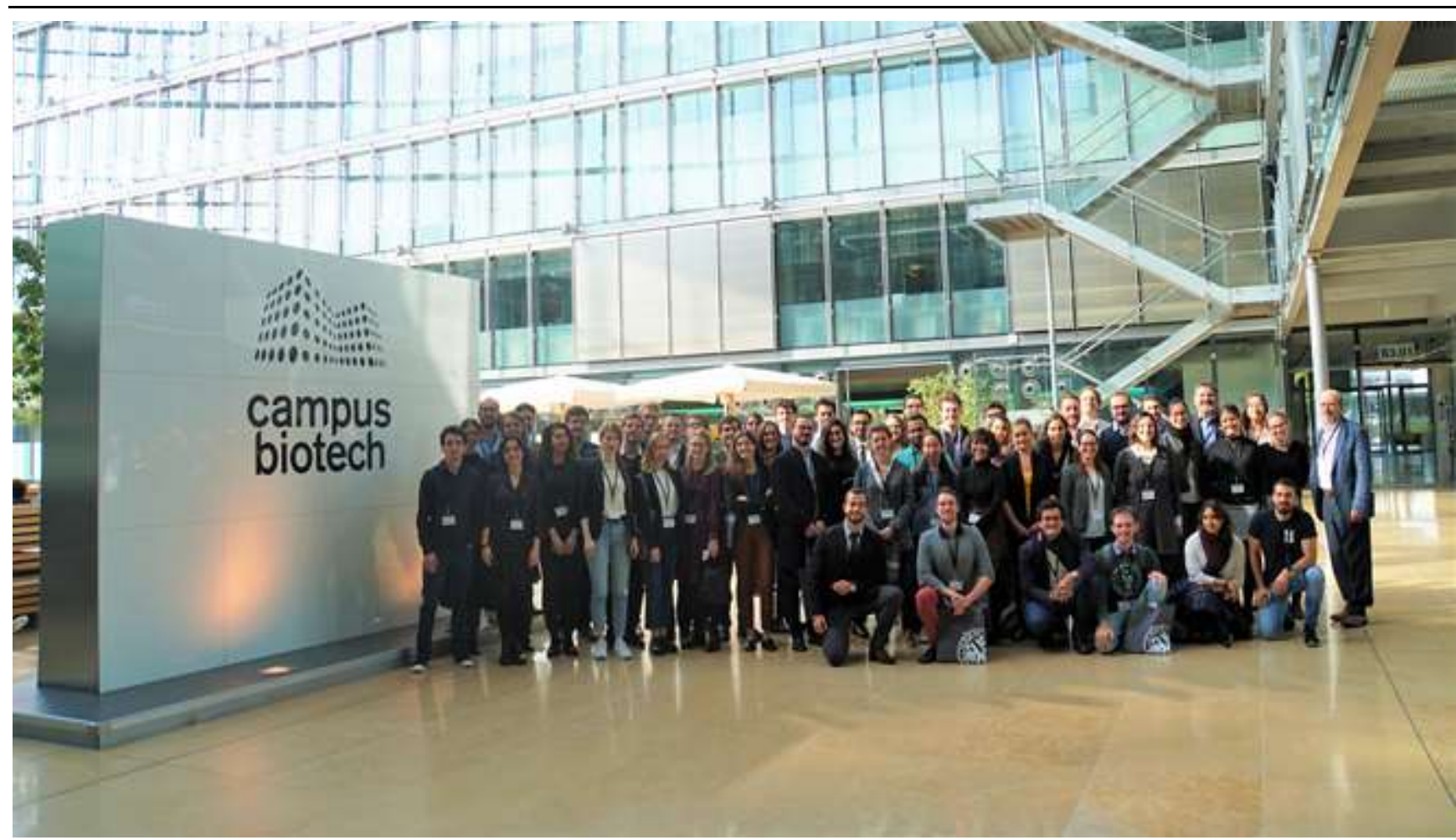

However, I would not dare to complain since a range of otherwise unattainable rewards revealed themselves along the way - jobs, positions, prizes at grants, the EMPA presidency - but the greatest reward is the respect and recognition from my physician peers whenever I go to seminars and conferences to present my experimental data.

PMR: In your opinion, what are the key features of an impactful or successful Physician-Scientist?

ADSR: This question has no easy answers. Through EMPA, I have had the chance to meet and interact with many colleagues from different countries, programmes and backgrounds. Each career seems so unique and they all are meant to lead to a successful physician-scientist profile. From my perspective, two aspects deserve special attention whether one wants to successfully combine clinics and research: career planning and mentorship. While your PhD is still ongoing, dedicate some time to discuss with your mentors your next steps and future plans, apply to grant opportunities and manage research protected time with your institution. I believe that these key features will help pave the way to a fruitful career.

\section{PMR: What are your future career and scientific aspirations?}

ADSR: Regarding medical training, I will pursue my Anaesthesiology $\mathrm{A}$ ICU specialised training. Simultaneously, I am managing a noninterventional clinical trial that aims to bridge and validate my preclinical data within clinical scenarios. I was lucky to be awarded Swiss National funding to support my research during residency and, therefore, I am planning to acquire clinical research skills alongside medical training. Regarding my long-term career aspirations, the plan is to take a path such that academia and research can accompany my clinical duties.

PMR: Can you tell us about the history of EMPA and where it found its origins?

ADSR: MD-PhD gatherings at the European level started in London in 2012. Back then, EMPA did not exist but the informal association between students from European MD-PhD programmes started by bringing together annual international MD-PhD conferences throughout Europe. It was in 2015, during the $4^{\text {th }}$ European MD-PhD Conference in Groningen, The Netherlands, that EMPA was born with an official registration in the Chamber of Commerce, its statutory terms, its Executive and Advisory Boards. The heritage from this "birth" is that our website servers, financial and legal headquarters are still in Groningen today.

\footnotetext{
University College Cork, Cork. Ireland.

European MD-PhD Association, Groningen, The Netherlands.

3 Department of Anesthesiology, Pharmacology and Surgery Intensive Care, University of Geneva, Geneva, Switzerland
}

About the Author: Paul MacDaragh Ryan is an incoming Academic Track Junior Doctor in Cork, Ireland. He holds a PhD which investigated the role of the gut microbiome in host cardiometabolic function. Paul is a current Evidence Synthesis Ireland Fellow and an Associate Editor at International Journal of Medical Students.

Correspondence:

Paul MacDaragh Ryan

Address: Gaol Walk, University College, Cork, T12 YN60, Ireland

Email: 108444161@umail.ucc.ie
Editor: Mihnea-Alexandru Găman Associate Editors: Ammar Ismail Submission: Feb 04, 2020 Acceptance: Feb 09, 2020 Publication: Apr 30, 2020 Process: Not Peer-reviewed 
PMR: When and how did you become involved in EMPA?

ADSR: It was back to 2017, when I attended the $6^{\text {th }}$ Swiss and European MD-PhD Conference in Basel. I got to know EMPA's goals and projects during the General Assembly and I was recruited to join the movement, just as happened to you in Geneva lately. By the way, thank you for becoming the National Representative for EMPA in Ireland.

PMR: You recently successfully orchestrated the 2019 European and Swiss MD-PhD Conference in the beautiful Campus Biotech setting of Geneva, Switzerland. Can you tell us a bit about this?

ADSR: Having joined EMPA in Basel as I mentioned, it was now my turn to bring the European MD-PhD Conference to Swiss ground once again and to spread EMPA's mission to new members from European Universities. In partnership with the Swiss MD-PhD Association, in which I am the international liaison, we co-organised the $8^{\text {th }}$ annual EMPA conference at Campus Biotech, the Life Sciences' Hub for the region of Lake Geneva (Figure 2). Dedicated to Biotechnology in Health, this year's conference gathered over 70 MD-PhD candidates and graduates, allowing young doctors to present their unique research work and to network with peers, while enjoying a rich scientific programme delivered by a range of experts in the field from across Europe and the United States.

PMR: What were the major highlights and take-home messages of the conference for you?

ADSR: The major highlight was the presence of more than 70 attendees, from 15 nationalities with a wide range of ages, backgrounds and interests. About twenty original scientific works were selected for oral presentation, in addition to a range of poster presentations, and the high quality of the research done by students during their PhD pursuits was remarkable. These pluralistic demographics is the proof that EMPA shall foster international collaborations, given the rich and highly diverse curricular framework throughout Europe.

PMR: While Europe was certainly the home to many of the first true physician-scientists, the United States was the first country to develop the formal MD-PhD program more than 50 years ago.' What is the current state of MD-PhD programs in Europe?

ADSR: Thanks for raising this issue, which is so dear to me. Indeed, the old Continent has certainly an older and richer scientific history, but for some reason we were far slower than our American peers in developing MD-PhD programmes. It was in the late 80's and early 90's that the first programmes appeared in the UK, France and Switzerland. Efforts have been growing (albeit slowly) ever since and other countries and universities have begun to design PhD programmes tailored for medical students and clinicians. Despite this, the current state in Europe could still be vastly improved, since many countries still lack these programmes entirely. In line with this, we have made it a priority of EMPA over the past few years to host national events and forums in different countries in order to promote tailored programmes for medical doctors wishing to follow PhD tracks.

PMR: What do you hope to achieve during your term as Chairman and what is the long-term future of EMPA?

ADSR: My biggest goal as chairman is to be a facilitator and promoto of international collaborations. In the past, the divergent design of MDPhD programmes in Europe created some divisions between countries. 3 To heal old wounds, we came up with a new definition and modified our statutes accordingly in 2019 to include in our ranks all health care professionals and students with an interest in biomedical research, in particular physicians, pharmacists and dentists.

As a most sincere personal and associative goal, I hope to achieve consortiums and consensus between the different players inside and outside Europe. I am happy to announce that we have been signing memorandums of agreement with many universities and associations to provide better network and training opportunities for our members. To mention just one, we established the International Consortium of Clinician Scientist Trainees' Organisation together with American, Canadian, Asian, French and Swiss physician-scientists associations. ${ }^{2}$

PMR: How can interested students find more information about EMPA and get involved in the organisation?

ADSR: We have several channels of communication through which we are eager to connect, such as Facebook, ${ }^{4}$ Twitter $^{5}$ and LinkedIn, ${ }^{6}$ along with our website, ${ }^{7}$ where an events calendar and useful information are continuously updated. Finally, I would be happy to receive and reply to any inquiries directly via the EMPA email address, eumdphdassociation@gmail.com. 


\section{Interview}

\section{References}

1. Harding CV, Akabas MH, Andersen OS. History and Outcomes of 50 Years of Physician-Scientist Training in Medical Scientist Training Programs. Acad Med. 2017; 92(10): 1390-8.

2. Association EMP. The International Consortium of Clinician Scientist Trainee Organizations Announcement. 2019 [cited 2020 04/02/2020]; Available from: https://www.eumdphd.com/icssto/.

3. Dos Santos Rocha A, Scherlinger M, Ostermann L, Mehler DMA, Nadiradze A, Schulze F, et al. Characteristics and opinions of MD-PhD students and graduates from different European countries: a study from the European MD-PhD Association. Swiss Med Wkly. 2020; 150: w20205.
4. Association EMP. EMPA Facebook Page. 2020 [cited 2020 04/02/2020]; Available from: https://www.facebook.com/eumdphd/.

5. Association EMP. EMPA Twitter Page. 2020 [cited 2020 04/02/2020]; Available from: https://twitter.com/eumdphd?lang=en.

6. Association EMP. EMPA LinkedIn Page. 2020 [cited 2020 04/02/2020]; Available from: https://www.linkedin.com/company/european-md-phdassociation/about/.

7. Association EMP. EMPA Homepage. 2020 [cited 2020 04/02/2020]; Available from: https://www.eumdphd.com/.

\section{Acknowledgments}

None.

Conflict of Interest Statement it Funding

The Authors have no funding, financial relationships or conflicts of interest to disclose.

Author Contributions

Conceptualization: PMR. Writing - Original Draft: PMR, and ADSR. Writing - Review \& Editing: PMR, and ADSR.

Cite as:

Ryan, PM, Dos Santos Rocha, A. Fostering Europe's Future Physician-Scientists: An Interview with European MD/PhD Association Chairman Dr. André dos Santos Rocha. Int J Med Students. 2020 Jan-Apr;8(1):45-48.

This work is licensed under a Creative Commons Attribution 4.0 International License

ISSN 2076-6327

This journal is published by the University Library System, University of Pittsburgh as part of the Digital Publishing Program and is co-sponsored by the University of Pittsburgh Press. 